\title{
ANALISA DAN IMPLEMENTASI KNOWLEDGE MANAGEMENT SYSTEM: STUDI KASUS DI SEKOLAH MENENGAH ATAS NEGERI 1 BAYANG
}

\author{
Ondra Eka Putra \\ Universitas Putra Indonesia YPTK Padang. Jalan Lubuk Begalung Padang. \\ Email: ondraekaputra@upiyptk.co.id
}

\begin{abstract}
Found lack of good management of knowledge School SMA Negeri 1 Bayang. Knowledge management is not good can cause a lack of knowledge transmission is only delivered directly. This is because the learning activities are only delivered face to face. Knowledge is one thing that is very important for students, teachers and employees at the school, the knowledge does not have to be obtained in person or face-to-face between teachers, students and employees who share knowledge. In this study will be designed a system that can manage knowledge so well that teachers, students and employees can share knowledge and information for the actors who needs although do not follow the forum directly to the knowledge management system, when students can not attend classes can still get the material from integrated system, delivery of information by the school can also be obtained by students although unable to attend school, the teacher can not attend a workshop or meeting can get the information or the results of the workshop or meeting.
\end{abstract}

Key words: knowledge management system, knowledge sharing and information

\section{PENDAHULUAN}

Ilmu pengetahuan merupakan kunci sukses dalam semua aspek di berbagai bidang. Seiring dengan perkembangan teknologi, dimana semua aspek kehidupan berbasis teknologi dan ini menjadi sebuah tantangan bagi sumber daya manusia (SDM) untuk menghadapi persaingan global. Ilmu pegetahuan menjadi harga mutlak yang harus dimiliki dan dimanajemen dengan baik.

Dunia pendidikan memiliki peranan penting sebagai media untuk membangun SDM yang berkualitas serta media untuk menuntut ilmu bagi anak penerus bangsa agar mempunyai pengetahuan yang luas. Pengetahuan yang menjadi sumber sukses suatu organisasi atau instansi perlu di manajemen dengan baik dalam wadah yang tersistem dengan membangun sebuah sistem yang dapat memanajemennya agar semua data setiap pelaku yang menggunakan, mencari serta memberikan pengetahuan dapat terintegrasi dengan baik sehingga hasilnya mudah untuk dimanfaatkan dengan knowledge management system.

Knowledge management dianggap sebagai suatu entitas yang sistematik yang berupaya memperluas, mengolah, dan menerapkan pengetahuan yang tersedia dengan cara memberikan nilai tambah pada entitas dalam mencapai tujuan. Knowledge management system diciptakan untuk memfasilitasi penangkapan, penyimpanan, pencarian, transfer dan penggunaan kembali pengetahuan

Sekolah Menengah Atas Negeri 1 Bayang ini merupakan suatu instansi pendidikan yang memiliki kewenangan dan tugas dalam pembinanaan dan penyelenggaraan pendidikan serta memiliki peranan dalam upaya mencerdaskan bangsa dengan manajemen pengetahuan yang baik. Kemajuan teknologi dan ilmu pengetahuan yang meningkat tentunya menjadi tantangan baru bagi sekolah yang harus 
mengelola aset-aset knowledge yang terintegrasi dengan berkolaborasi dan inovasi yang akan mendorong penciptaan knowledge management, namun sebagian besar knowledge yang ada pada sekolah saat ini sulit untuk disimpan dalam suatu sistem karena knowledge lebih bersifat individual saja. Sistem training atau workshop yang berjalan tidak memiliki media peyimpanan dan tidak adanya transfer knowledge trainning dan knowledge management, akibatnya guru yang tidak mengikuti training tersebut tidak mengetahui hasil training dan bagi siswa tidak dapat memanfaatkan pengetahuan yang seharusnya diketahui.

Berdasarkan latar belakang yang telah diuraikan, maka dapat dibuat perumusan masalah sebagai berikut:

1. Bagaimana knowledge management system dapat dijadikan media untuk berbagi data, informasi maupun knowledge dilingkungan SMAN 1 Bayang ?

2. Apakah dengan adanya knowledge management system dapat meningkatkan efektifitas kegiatan dalam mencari suatu ilmu pengetahuan pada SMAN 1 Bayang?

3. Bagaimana menghasilkan informasi yang tepat waktu, akurat serta bebas dari manipulasi data, baik untuk pihak intern maupun ekstern yang membutuhkan data dalam knowledge management system?

4. Bagaimana merancang knowledge management system yang dapat di akses melalui website?

5. Bagaimana merancang suatu sistem yang dapat membantu guru dan pegawai melakukan knowledge sharing (berbagi pengetahuan)?

\section{Konsep Dasar Sistem Informasi Pengertian Sistem}

Menurut Jogiyanto (2009:34), sistem (system) dapat didefinisikan dengan pendekatan prosedur dan dengan pendekatan komponen. Dengan pendekatan prosedur, sistem dapat di definisikan sebagai kumpulan dari prosedurprosedur yang mempunyai tujuan tertentu. Suatu sistem dapat terdiri dari sistem-sistem bagian (subsystems). Sebagai misalnya, sistem komputer dapat terdiri dari subsistem perangkat keras dan subsistem perangkat lunak.
Masing-masing subsistem dapat terdiri dari subsistem-subsistem yang lebih kecil lagi atau terdiri dari komponen-komponen. Subsistem perangkat keras (hardware) dapat terdiri dari alat masukan, alat pemroses, alat keluaran dan simpanan luar. Subsistem subsistem saling berinteraksi dan saling berhubungan membentuk satu kesatuan sehingga tujuan atau sasaran sistem tersebut dapat tercapai. Interaksi dari subsistemsubsistem sedemikian rupa, sehingga dicapai suatu kesatuan yang terpadu dan terintegrasi (integrated).

\section{Pengertian Informasi}

Di dalam suatu organisasi, informasi merupakan sesuatu yang memiliki arti yang sangat penting di dalam mendukung proses pengambilan keputusan oleh pihak manajemen.

Informasi (information) didefinisikan oleh Davis dalam Abdul Kadir (2014:45) adalah data yang telah diolah menjadi sebuah bentuk yang berarti bagi penerimanya dan bermanfaat dalam pengambilan keputusan saat ini atau saat mendatang.

Sumber dari informasi adalah data. Data adalah deskripsi tentang benda, kejadian, aktivitas dan transaksi yang tidak mempunyai makna atau tidak berpengaruh secara langsung kepada pemakai (Abdul Kadir, 2014:44).

Informasi yang baik tentunya informasi yang berkualitas, kualitas informasi sangat ditentukan oleh hal-hal berikut, yaitu:

1. Akurat, berarti informasi harus bebas dari kesalahan-kesalahan atau menyesatkan penerima informasi. Akurat juga dapat berarti jelas akan mencerminkan maksudnya.

2. Tepat waktu, berarti informasi yang diterima harus tepat waktu, karena informasi yang kadaluarsa tidak akan mempunyai nilai lagi. Karena informasi merupakan landasan di dalam pengambilan keputusan, bila terlambat dapat berakibat fatal untuk organisasi.

3. Relevan, berarti informasi tersebut mempunyai manfaat untuk penerimanya. Misalnya informasi mengenai kerusakan mesin produksi ditujukan kepada akuntan perusahaan adalah kurang relevan tetapi akan lebih relevan bila ditujukan pada ahli teknik 
perusahaan. Sabaliknya informasi mengenai harga pokok produksi untuk ahli teknik merupakan informasi yang kurang relevan, tetapi relevan untuk seorang akuntan.

Nilai informasi ditentukan dari dua hal yaitu manfaat dan biaya mendapatkannya. Suatu informasi dikatakan bernilai bila manfaatnya lebih besar dan efektif bila dibandingkan dengan biaya untuk mendapatkannya. Akan tetapi perlu diperhatikan bahwa informasi yang digunakan didalam suatu sistem informasi umumnya digunakan untuk beberapa kegunaan. Adapun kegunaan informasi adalah sebagai berikut:

a. Meningkatkan pengetahuan penerimanya.

b. Memperjelas masalah atau perintah.

c. Meningkatkan probabilitas dalam membuat keputusan manajemen.

\section{Pengertian Sistem Informasi}

Untuk mendapatkan informasi yang diinginkan tentunya harus menggunakan sistem informasi. Sistem informasi dalam suatu organisasi dapat dikatakan sebagai suatu sistem yang menyediakan informasi bagi semua tingkatan dalam organisasi tersebut kapan saja diperlukan. Sistem ini menyimpan, mengambil, mengubah, mengolah dan mengkomunikasikan informasi yang diterima dengan menggunakan sistem informasi atau peralatan sistem lainnya.

Menurut Hall (Abdul Kadir,2014:9) Sistem informasi adalah sebuah rangkaian prosedur formal dimana data dikelompokkan, diproses menjadi informasi, dan didistribusikan kepada pemakai.

Dari pendapat di atas dapat diambil kesimpulan bahwa sistem informasi adalah kumpulan elemen-elemen yang saling berhubungan yang digunakan untuk mengumpulkan data, kemudian memproses data itu menjadi informasi yang akan didistribusikan kepada penggunanya untuk dijadikan bahan untuk pengambilan keputusan.

Menurut Jogiyanto (2009:42), sebuah sistem informasi terdiri dari beberapa komponen, yaitu:

1. Komponen Input

Input mewakili data yang masuk ke dalam sistem informasi. Input disini termasuk metode-metode dan media untuk menangkap data yang akan dimasukkan, yang dapat berupa dokumen-dokumen dasar.

2. Komponen Output

Produk dari sistem informasi adalah output yang merupakan informasi yang berkualitas dan dokumentasi yang berguna untuk semua tingkatan manajemen serta semua pemakai sistem.

3. Komponen Basis Data

Basis data (database) merupakan kumpulan dari data yang saling berhubungan satu dengan yang lainnya, tersimpan di perangkat keras komputer dan digunakan perangkat lunak untuk memanipulasinya. Data perlu disimpan di dalam basis data untuk keperluan penyediaan informasi lebih lanjut. Data di dalam basis data perlu diorganisasikan sedemikian rupa, supaya informasi yang dihasilkan berkualitas. Organisasi basis data yang baik juga berguna untuk efisiensi kapasitas penyimpanannya. Basis data diakses atau dimanipulasi dengan menggunakan perangkat lunak paket yang disebut dengan DBMS (Database Management Systems).

4. Komponen Model

Blok ini terdiri dari kombinasi prosedur, logika dan model matematik yang akan memanipulasi data input dan data yang tersimpan di basis data dengan cara yang sudah tertentu untuk menghasilkan keluaran yang diinginkan.

5. Komponen Teknologi

Teknologi merupakan "kotak alat" (toolbox) dalam sistem informasi. Tekonologi digunakan untuk menerima input, menjalankan model, menyimpan dan mengakses data, menghasilkan dan mengirimkan keluaran dan membantu pengendalian dari sistem secara keseluruhan. Teknologi terdiri dari 3 bagian utama, yaitu teknisi (humanware atau brainware), perangkat lunak (software) dan perangkat keras (hardware). Teknisi dapat berupa orangorang yang mengetahui teknologi dan membuatnya dapat beroperasi. Misalnya teknisi adalah operator computer, pemrogram dan lain sebagainya.

6. Komponen Kontrol 
Banyak hal yang dapat merusak sistem informasi, seperti misalnya bencana alam, api, temperatur, air, debu, kecurangan-kecurangan, kegagalankegagalan sistem itu sendiri, kesalahankesalahan, ketidak efisienan, sabotase dan lain sebagainya. Beberapa pengendalian perlu dirancang dan diterapkan untuk meyakinkan bahwa hal-hal yang dapat merusak sistem dapat dicegah ataupun bila terlanjur terjadi kesalahan-kesalahan dapat langsung cepat diatasi.

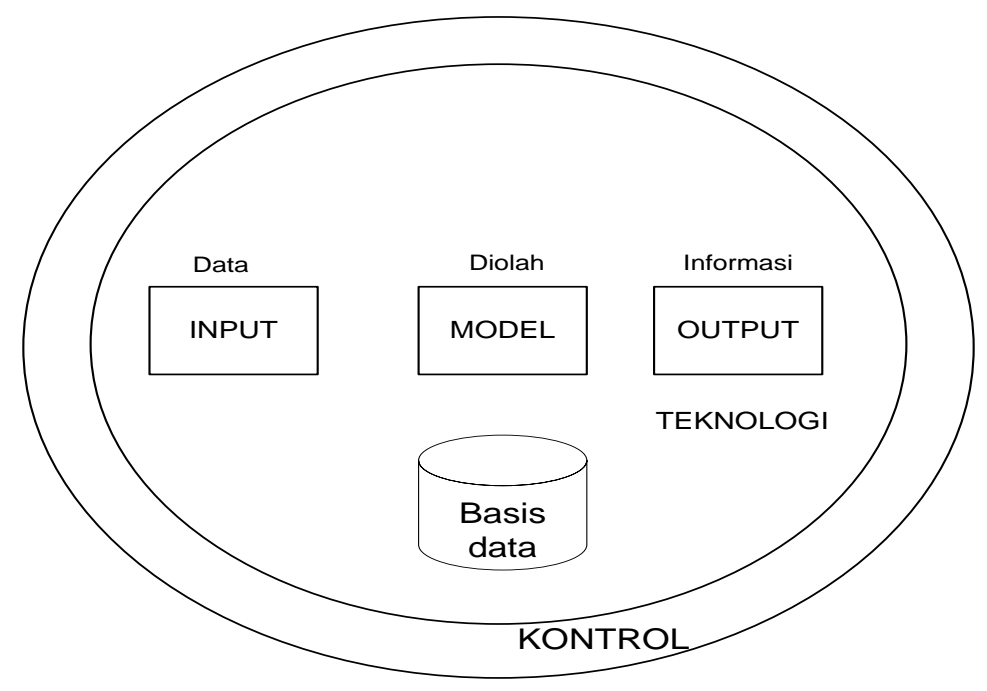

Gambar 1 Komponen-komponen sistem informasi (Sumber: Jogiyanto, 2009:43)

\section{Knowledge Management Pengetahuan) Knowledge}

Knowledge atau pengetahuan adalah hasil dari rangakaian bagaimana kita memproses data mentah menjadi informasi yang berguna Data dan informasi yang berguna. Data dan infomasi yang disaring lebih jauh berdasarkan fakta, kebenaran, kepercayaan, penilaian, pengalaman dan keahlian si penerima.

Menurut Atter, pengetahuan (knowledge) merupakan kombinasi dari naluri, gagasan, atura da prosedur yang mengarahkan tindakan atau keputusan. Informasi yang di padukan dengan pengalaman masa lalu dan kealian akan memberikan suatu pengetahuan yang bernilai tinggi (Mulyanto,2009:19).

Pengetahuan memiliki derajat paling tinggi dibandingkan dengan data informasi, tetapi dari segi kualitas pengetahuan memiliki uantitas yanglebih sedikit dibandingkan daa dan informasi.

\section{Siklus Knowledge}

1. Sosialisasi

Merupakan proses sharing dan penciptaan tacit kowledge melalui interaksi dan pengalaman langsung.

2. Externalisasi

Merupakan pengartikulasian tacit knowledge menjadi explicit knowledge melalui proses dialog dan refleksi.

3. Kombinasi

Merupakan konversi explicit knowledge menjadi explicit knowledge yang baru melalui sistemisasi dan pengaplikasian explicit knowledge dan informasi.

4. Internalisasi 
Merupakan proses pembelajaran dan akusisi knowledge yang dilakukan oleh anggota organisasi terhadap explicit knowledge yang disebarkan keseluruh organisasi melalui pengalaman sendiri siehingga menjadi tacit knowledge anggota organisasi.

\section{Managemen}

Manajemen adalah suatu tim yang disusun dalam organisasi unuk menjadi pengendali organisasi untuk mencapai tujuantujuan dan sasaran-sasaran yang hendak dicapai oleh organisasi (Nugroho,2008:57).

Definisi lai dari manajemen adalah proses mengkoordinasikan, mengintegrasikan, menyederhanakan, dan mensinkronisasikan smber daya manusia, material dan metode dengan mengaplikasikan fungsi-fungsi manajemen seperti -perencanaan, pengorganisasian, penggiatan, pengawasan, dan lain-lain agar tujuan orgaisai dapat tercapa secara efisien dan efektif (Amsyah,2005:59).

Berikut ini adalah beberapa fungsi managemen:

a. Perencanaan

Dalam perencanaan ini adanya emilihan tujuan da peneta-an kebijakan, prosedur, dan program-program untuk mencapainya.

b. Pengorganisasian

Pengelompokkan kegiatan-kegiatan yang harus dilaksanakan dan menetapkan bentuk serta hubungan keorganisasian untuk menjalankan kegiatan.

c. Penyusunan Staff

Pemilihan dan pelatihan orang untuk bekerja dalam organisasi.

d. Pengkoordinasian

Penjadwalan kegiatan-kegiatan dalam urutan-urutan yang tepat.

e. Pengarahan

Pemimpin, pemberian pedoman, pengarahan, dan pemotivasian orag dalam oganisasi.

f. Pengendalian

Pengukuran prestasi, pengaturan dan pebenaran kegiatan, kebijakan, prosedur dan program.

\section{Knowledge Management}

Beberapa definisi Kowledge Management ditinjau dari segi para ahli adalah sebagai berikut:

a. Menurut Davidson dan Voss, knowledge management adalah sistem yang memungkinkan peusahaan meyerap pengetahuan, pengalaman, dan kreatifitas para stafnya untuk perbaikan kinerja perusahaan (Ghalia Indonesia, 2012:2)

b. Menurut Batgerson, knowledge management merupakan suatu pendekatan yang sistematik untuk mengelola aset intelektual dan informasi lain sehingga memberikan keunggulan bersaig bagi perusahaan(Ghalia Indonesia, 2012:2).

c. Menurut De Long dan Seemann, manajemen pengetahuan digambarkan sebagai pengemangan alat, proses, sistem, struktur, dan kultur yang secara implisit meningkatkkan kreasi, penyebaran dan pemanfaatan pengethuan yang penting bagi pengambilan keputusan (Ghalia Indonesia, 2012:2).

Dari berbagai sudut pandang yang berbedabeda mengenai definisi knowledgemanagement (manajemen pengetahuan) diatas, maka Tannabaum (Ghalia Indonesia,2012:2). Mengemukakan definisi manajemen pengetahuan sebagai suatu sonsensus sehingga memiliki pemahaman yang lebih komprehensif yaitu:

a. Menajemen pengetahuan mencakup pengumpulan, penyusunan, penyimpanan dan pengaksesan informasi untuk memabangun pengetahuan.

b. Manajemen pengetahuan mencakup berbagi pengetahuan (sharing knowledge), tanpa berbagi pengetahuan upaya manajemen pengetahuan tentu akan gagal.

c. Manajemen pengetahuan terkait dengan orang. Pada suatu saat, organisasi mmbutuhkan orang-orang yang kompeten untuk memahami dan memanfaatkan informasi dengan efektif.

d. Manajemen pengetahuan terkait ddengan penigkatan efektivitas organisasi.

\section{Knowledge Management System}

Knowledge Management System atau sistem manajemen pengetahuan adalah suatu 
sistem teknologi informasi dan komunikasi dalam pengertian sebuah sistem aplikasi yang mengkombinasikan dan mengintegrasikan fungsi untuk sebuah perlakuan kontekstual terhadap masing-masing pengetahuan eksplisit dan tasit, selama sebuah organisasi atau sebagian organisasi tersebut menjadi target dari tindakan manajemen pengetahuan. Tujuan utama dari KMS adalah untuk mendukung dinamika pembelajaran organisaonal dan keefektifan organisasi tersebut.

KMS dapat ditinjau dari berbagai sudut pandang berbeda, antara lain:

1. Berfokus terhadap dukungan TIK untuk sebuah siklus hidup KM dan atau instrumen organisasi tertentu yang diterapkan sebagai bagian dari tindakan manajemen pengetahuan.

2. Berfokus pada analogi yang diusulkan antara manusia dan pemrosesan serta pembelajaran informasi yang bersifat organisasional.

3. Meninjau ulang seperangkat fungsi yang menjadi bagian dari KMS sebagaimana yang telah ditawarkan di pasaran.

4. Adanya ekstensi atau integrasi terhadap perangkat lunak yang ada, seperti solusi intranet, sistem pengelolaan dokumen, sistem pengelolaan alur workflow, perangkat kelompok dan sistem komunikasi

\section{METODE DAN HASIL PENELITIAN Use case Diagram}

Use case Diagram, menggambarkan sekelompok Use cases dan aktor yang disertai dengan hubungan diantaranya. Diagram Use cases ini menjelaskan dan menerangkan kebutuhan atau requirement yang diinginkan user, serta sangat berguna dalam menentukan struktur organisasi dan model dari pada sebuah sistem. Use case diagram dapat sangat membantu bila kita sedang menyusun requirement sebuah sistem, mengkomunikasikan rancangan dengan klien, dan merancang test case untuk semua feature yang ada pada sistem.

Sebuah use case dapat meng-include fungsionalitas use case lain sebagai bagian dari proses dalam dirinya. Secara umum diasumsikan bahwa use case yang di-include akan dipanggil setiap kali use case yang meng-include dieksekusi secara normal. Sebuah use case dapat di-include oleh lebih dari satu use case lain, sehingga duplikasi fungsionalitas dapat dihindari dengan cara menarik keluar fungsionalitas yang common. Sebuah use case juga dapat meng-extenduse case lain dengan behaviour-nya sendiri. Sementara hubungan generalisasi antar use case menunjukkan bahwa use case yang satu merupakan spesialisasi dari yang lain. Use case system dapat dilihat pada Gambar 2.

\section{Class Diagram}

Class diagram menampilkan eksistensi atau keberadaan dari class-class dan hubungan (relationship) dalam desain logikal dari sebuah sistem. Class adalah sebuah spesifikasi yang jika diinstansiasi akan menghasilkan sebuah objek dan merupakan inti dari pengembangan dan desain berorientasi objek. Class menggambarkan keadaan (atribut/properti) suatu sistem, sekaligus menawarkan layanan untuk memanipulasi keadaan tersebut (metoda/fungsi).

Class diagram menggambarkan struktur dan deskripsi class, package dan objek beserta hubungan satu sama lain seperti containment, pewarisan, asosiasi, dan lain-lain. Class memiliki tiga area pokok, yaitu nama (dan stereotype), atribut dan metoda. Atribut dan metoda dalam Class Diagram dapat memiliki salah satu sifat berikut :

1. Private, tidak dapat dipanggil dari luar class yang bersangkutan

2. Protected, hanya dapat dipanggil oleh class yang bersangkutan dan anak-anak yang mewarisinya

3. Public, dapat dipanggil oleh siapa saja

Bentuk class diagram pada knowledge management SMA N 1 Bayang dapat dilihat pada Gambar 3. 


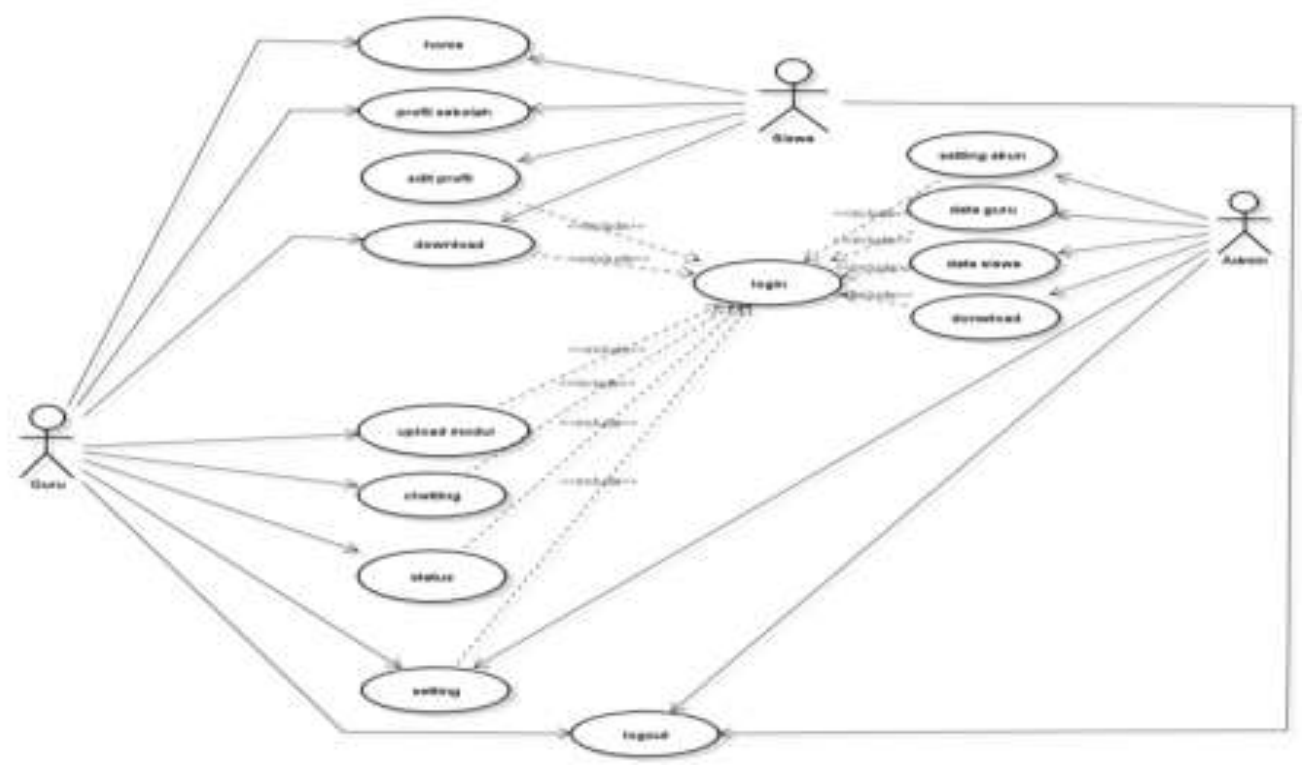

Gambar 2 Use Case Diagram

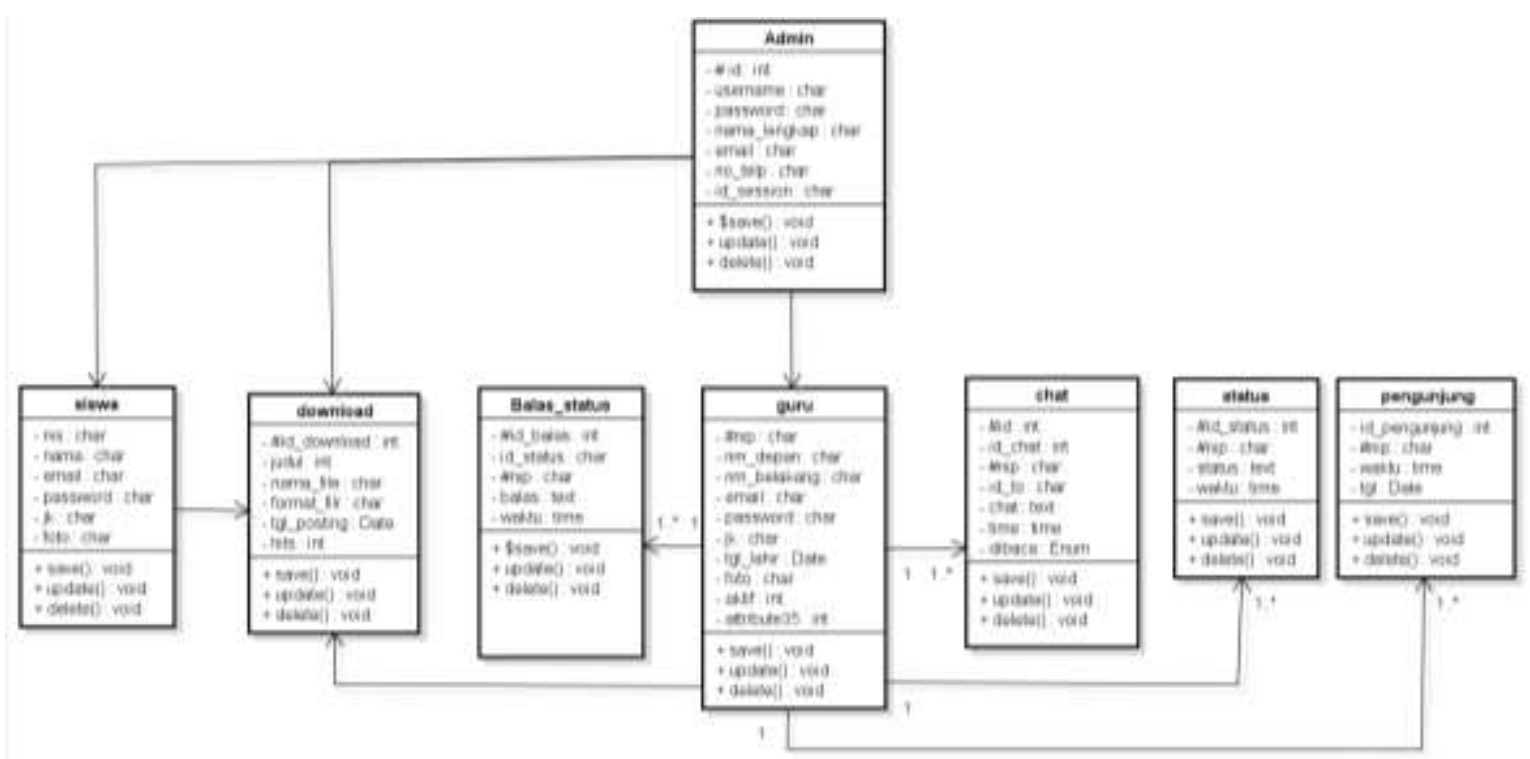

Gambar 3 Class Diagram

\section{Pengujian Sistem}

Pada pengujian memperlihatkan cara sistem ini akan menjalankan atau mengoperasikan program aplikasi yang telah dirancang.

Tampilan Entry Upload Bahan 
Tampilan ini menampilkan entry upload bahan yang dapat di digunakan oleh siswa serta user lainya agar dapat mendownload file yg di upload oleh guru yang dapat dilihat pada Gambar 4.

\section{Tampilan Data Chatting}

Pada tampilan data chatting ini digunakan untuk melakukan chatting pada sesama guu yang dapat dilihat pada Gambar 5.

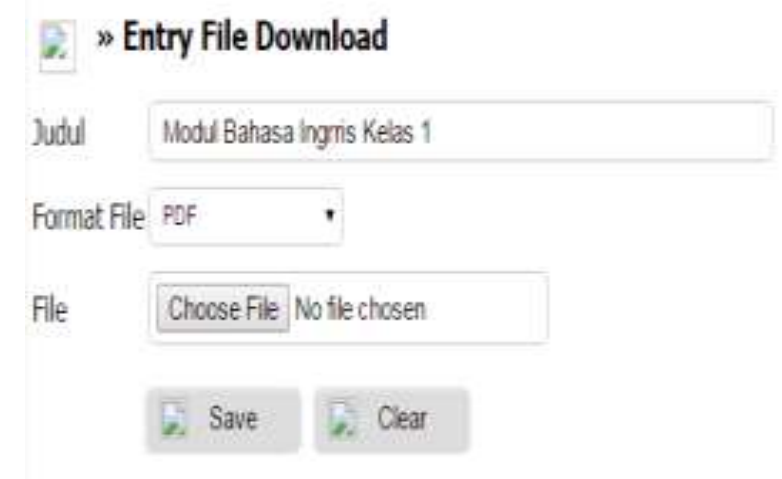

Gambar 4 Tampilan Entry Upload Bahan

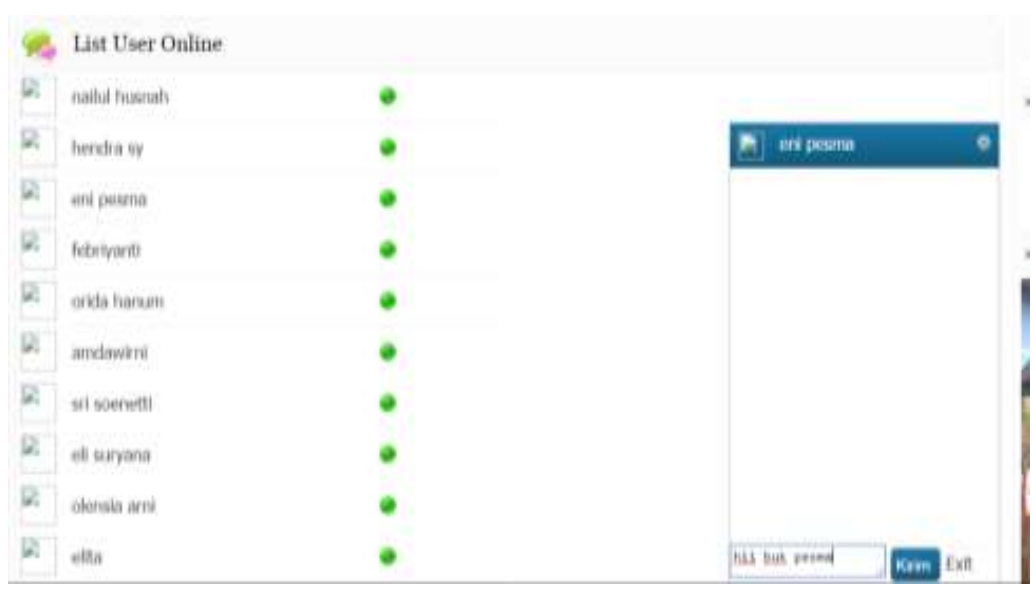

Gambar 5 Tampilan Chatting

\section{Tampilan Data Status}

Pada tampilan ini sesama guru bisa melakukan diskusi, balas komentar dan hapus komentar yang dapat dilihat pada Gambar 6.

\section{Tampilan View dan Download Modul}

Tampilan form download modul yang harus di lakukan oleh siswa setelah melakukan login yang terlihat pada Gambar 7. 


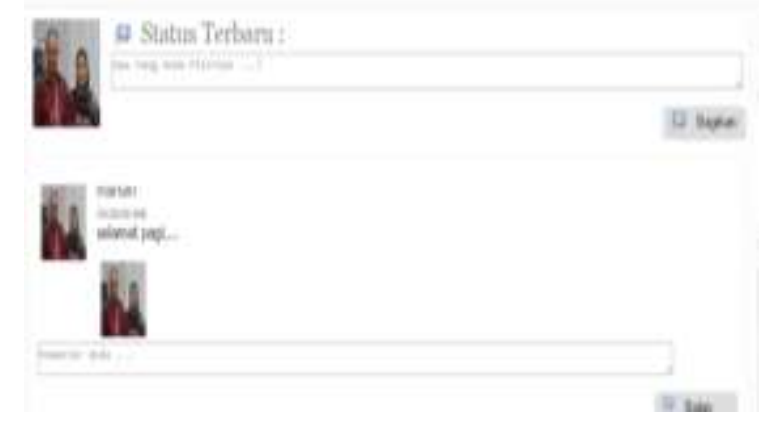

Gambar 6 Tampilan Data Status

\begin{tabular}{|c|c|c|c|}
\hline \multicolumn{4}{|c|}{ DATA MATERI DOWNLOAD } \\
\hline No Judul & Fomiat File & Tgl Posting & File \\
\hline 1 binggris & PPT & $2014-05-01$ & Vew \& Dawnlosd \\
\hline $2 \mathrm{IPA}$ & PDF & $2014-05-01$ & Vew \& Download \\
\hline 3 Agama & PDF & $2014-05-01$ & View \& Dowrload \\
\hline 4 Matematika & PDF & $2014-05-01$ & Vew \& Dowricad \\
\hline $5 \mathrm{ppkn}$ & PDF & $2015-12-09$ & Vew \& Download \\
\hline
\end{tabular}

Gambar 7 Tampilan Download Modul

\section{KESIMPULAN}

Sebagaimana yang telah dikemukakan sebelumnya dan kemudian dilanjutkan dengan pembahasan masalah serta berdasarkan hasil yang didapat dari penelitian sistem informasi Knowledge Management pada SMA N 1 Bayang, maka dapat diambil beberapa kesimpulan sebagai berikut:

1. Dengan menggunakan PHP dapat mempermudah proses knowledge management pada SMA N 1 Bayang maka informasi yang di hasilkan dapat lebih cepat dan akurat.

2. Keamanan data lebih terjamin karena data di simpan dalam database.

3. Memudahkan sesama guru untuk mendapatkan informasi yang berkaitan dengan knowledge management karena dapat diakses secara online.

4. Mempermudah siswa mendapatkan informasi pengetahuan pembelajaran melalui modul-modul yang diberikan guru pada knowledge management.

\section{DAFTAR KEPUSTAKAAN}

Shalahuddin, Rosa A.S M. 2014. Rekayasa Perangkat Lunak. Bandung.

Al Fatta, Hanif. 2007. Analisis Dan Perancangan Sistem Informasi. Yogyakarta. Andi Offset.

Kadir, Abdul. 2014. Dasar Pemrograman Web Dinamis Menggunakan PHP. Yogyakarta: Andi Offset.

Munawar. Pemodelan Visual dengan $U M L$. Yogyakarta: Graha Ilmu 
Nawawi, Ismail. 2012.Manajemen Pengetahuan. Jakarta:Ghalia Indonesia.

Nugroho, Bunafit. 2009. Membuat Website Sendiri dengan PHP-MySQL.Mediakita. Jakarta

Oetomo, Dharma. Sutedja, Budi .2006. Perancangan dan Pembangunan Sistem Informasi. Yogyakarta: Andi Offset.
Sugiarti, Yuni. 2013. Analisis dan Perancangan UML (Unified Modelling Language). Yogyakarta: Graha Ilmu

Sutabri, Tata. 2012. Pengenalan Sistem Informasi. Jakarta : Elex Media Komputindo 